\title{
Effects of Visual Stimuli from Media on the Perception of Dentofacial Esthetics
}

\section{Utjecaj vizualnih podražaja iz medija na percepciju dentofacijalne estetike}

\author{
${ }^{1}$ Public Health Center Karlovac \\ Dom zdravlja Karlovac, Hrvatska \\ 2 University of Rijeka, Faculty of Dental Medicine, Department of Prosthodontics, Rijeka, Croatia and J. J. Strossmayer University of Osijek, \\ Faculty of Dental Medicine and Health, Department of Dental Medicine 2, Osijek, Croatia \\ Katedra za stomatološku protetiku Fakulteta dentalne medicine Sveučilišta u Rijeci, Hrvatska i Katedra za dentalnu medicinu 2 Fakulteta za \\ dentalnu medicinu i zdravstvo Sveučilišta J. J. Strossmayera u Osijeku, Hrvatska \\ 3 Public Health Center Rijeka \\ Dom zdravlja Primorsko-goranske županije, Rijeka, Hrvatska \\ ${ }^{4}$ University of Rijeka, Faculty of Dental Medicine, Department of Orthodontics, Rijeka, Croatia \\ Katedra za ortodonciju Fakulteta dentalne medicine Sveučilišta u Rijeci, Hrvatska \\ ${ }^{5}$ University of Rijeka, Faculty of Dental Medicine, Department of Orthodontics, Rijeka, Croatia and J. J. Strossmayer University of Osijek, Faculty \\ of Dental Medicine and Health, Department of Dental Medicine 1, Osijek, Croatia \\ Katedra za ortodonciju Fakulteta dentalne medicine Sveučilišta u Rijeci i Katedra za dentalnu medicinu Fakulteta za dentalnu medicinu i \\ zdravstvo Sveučilišta J. J. Strossmayera u Osijeku, Hrvatska
}

\section{Abstract}

Objectives: The study explored whether television commercials change the perception of one's own dentofacial attractiveness and to identify if it is influenced by personality traits. Material and methods: The sample included 83 participants, aged $19-27$ years. The experimental group $(\mathrm{N}=42)$ watched commercials portraying famous young individuals with high smile esthetics, bright teeth and no visible malocclusions, while the control group $(\mathrm{N}=41)$ watched neutral commercials (without people or visible teeth). The perception of subjects 'own orofacial esthetics and its psychosocial effects were assessed a month before the exposure and immediately after it. The subjects` malocclusion severity and personality characteristics (extraversion, conscientiousness, agreeableness, neuroticism, intellect, self-esteem and perfectionism) were assessed. Results: In their second report, respondents were inclined to report less psychosocial impacts with small differences (ranging from 0-3 scalar points on average) and less significant in the active group compared to neutral group ( 2 out of $7 \mathrm{vs}$. 5 out of 7 aspects). Types of visual stimuli were a significant predictor only of changes pertaining to psychological impact of dental esthetics $(p=0.045 ; r=0.221)$. The intellect moderated perception of smile esthetics, after having been exposed to commercials, accentuated beautiful smiles as a suppressor $\left(\Delta R^{2}=0.076 ; p=0.005\right.$; total model $\left.R^{2}=0.347 ; p=0.033\right)$. In subjects with higher cognitive abilities, an increase in the self-perceived malocclusion level induced a smaller decrease in psychological impact of dental esthetics as compared to those with lower intellect. Conclusion: Psychosocial influences of malocclusion are not stable and tend to decrease during time. However, the exposure to a high smile esthetic of other individuals can inhibit that process in persons with more severe malocclusion and higher cognitive abilities.
Received: February 17, 2020

Accepted: June 19, 2020

Address for correspondence Stjepan Spalj

University of Rijeka, Faculty of Dental Medicine

Department of Orthodontics

Kresimirova 40, 51000 Rijeka, Croatia

Phone: +385-51-345-638

stjepan.spalj@fdmri.uniri.hr

Key words

Advertisement; Dental Esthetics; Visual Perception; Malocclusion; Personality

\section{Introduction}

Media play significant roles in information dissemination and idealized images on how to obtain a perfect external appearance $(1,2)$. Marketing commercials are designed to provoke emotions often by using smile with visible teeth, which is associated with joy and pleasant social interactions $(3,4)$. Therefore, the content of visual stimuli, through media, is partly responsible for self-appraisal (5-7). A television commercial is a form of advertising, usually a short form of 30 seconds in duration, which conveys a message promoting,

\section{Uvod}

Mediji su važni u širenju informacija i idealiziranih slika o tome kako postići savršen vanjski izgled $(1,2)$. Marketinške poruke osmišljene su da potiču emocije često s pomoću osmijeha te $s$ vidljivim zubima, što je povezano s radošću i ugodnim društvenim interakcijama $(3,4)$. Tako je sadržaj vizualnih podražaja posredovan putem medija djelomično odgovoran za procjenu samoga sebe $(5-7)$. Televizijska reklama oblik je oglašavanja i obično je kratka - do 30 sekunda i prenosi poruku koja promiče proizvod ili uslugu, a čiji je cilj 
and aiming to market, a product or service. Even a short period of watching television programs and commercials can alter the cognition of appearance in women and majority would like to obtain this ideal beauty that is portrayed on television $(1,8)$.

Media stereotypes provided by images of superior beauty play a central role in creating and deteriorating body dissatisfaction. Furthermore, media stereotypes create and maintain a relation between the ideal of having a slim body and positive attributes such as sense of control, success and attractiveness (9). Dissatisfaction and shame is created when comparisons are made between the media ideals and people's own ideals (9). Accordingly, it has been proven that ideal images in media are associated with low self-esteem, lower satisfaction with physical appearance, and depressive behavior in females (2).

The face is considered to be a more important factor for overall attractiveness than the body, thus influencing one's self-esteem, social adjustment and integration (10). Patients wishing to undergo orthognathic surgery often express dissatisfaction with one or more aspects of their face implying that esthetic concern is probably the most prominent motive for surgery (11).

The aim of the study was to investigate to what extent media influence the perception of dentofacial esthetics. In other words, the aim was to investigate into how commercials that promote products that use the smile and teeth in the context of a positive and desirable outcome, are changing the satisfaction with their teeth, smile appearance, and social and emotional effects of smile attractiveness. In addition, the aim was to explore whether this relationship is influenced by an objective clinical condition and whether this process is influenced by personality traits and gender.

It was hypothesized that a decrease in satisfaction with one's own dentofacial appearance, and an increase in psychosocial impacts after the exposure to positive visual stimuli, is probably higher in females with higher self-perceived malocclusion severity, perfectionism, neuroticism, and lower selfesteem.

\section{Material and methods}

Our research design was experimental with two parallel groups. At first, it was supposed to include 90 subjects, first to fifth year dental students from the University of Rijeka in the age range of 19-27 years. The inclusion criteria were: having natural teeth from first molar to first molar in both jaws. The exclusion criteria were: orthodontic treatment, anterior restorations and syndromes. The research was undertaken with the understanding and written consent of each participant and in full accordance with ethical principles. Approval for this study was given by the Ethics Committee of the Faculty of Medicine Rijeka (2170-24-01-15-05). The subjects were randomly assigned to two groups of 45 respondents using the function "random between" in the Microsoft Excel software. The estimation of the sample size was based on previous research (12). Paired difference of means of Psychosocial Impact of Dental Aesthetics Questionnaire (PIDAQ) dimensions in a repeated administration of instrument without tržište. Čak i kratko gledanje televizijskih programa i reklama može promijeniti spoznaju o vlastitu izgledu kod žena, a većina bi željela približiti se idealu ljepote koji se prikazuje na televiziji $(1,8)$.

Medijski stereotipi koji stvaraju slike vrhunske ljepote imaju glavnu ulogu u nezadovoljstvu slikom tijela. Nadalje, medijski stereotipi stvaraju i održavaju odnos između ideala vitkog tijela i pozitivnih osobina poput osjećaja kontrole, uspjeha i atraktivnosti (9). Nezadovoljstvo i sram nastaju kad se uspoređuju medijski ideali s vlastitima (9). U skladu s tim dokazano je da su idealne slike u medijima povezane s niskim samopoštovanjem žena, njihovim nižim zadovoljstvom tjelesnim izgledom i depresivnim ponašanjem (2).

Lice se smatra važnijim čimbenikom kad je riječ o ukupnoj privlačnosti negoli tijelo i utječe na samopoštovanje, prilagođavanje i integraciju u društvo (10). Pacijenti koji se žele podvrgnuti ortognatskoj kirurgiji često navode nezadovoljstvo $s$ jednim ili više aspekata svojega lica, što implicira da je zabrinutost zbog estetike vjerojatno najistaknutiji motiv za operaciju (11).

Svrha studije bila je istražiti u kojoj mjeri mediji utječu na percepciju dentofacijalne estetike. Drugim riječima, kako reklame koje promoviraju proizvode osmijehom i vidljivim zubima u kontekstu pozitivnog i poželjnog ishoda, mijenjaju zadovoljstvo izgledom vlastitih zuba i osmijeha te društvene i emocionalne učinke atraktivnosti osmijeha. Uz to, željeli smo istražiti djeluje li na taj odnos objektivno kliničko stanje te utječu li na taj proces osobine ličnosti i spol.

Pretpostavljeno je da je smanjenje zadovoljstva zbog izgleda vlastitih zuba i lica te porast psihosocijalnih utjecaja nakon izlaganja pozitivnim vizualnim podražajima vjerojatno veće kod žena s višim intenzitetom samoopažene malokluzije, višim perfekcionizmom i neurotizmom, a nižim samopoštovanjem.

\section{Materijali i metode}

Ustroj istraživanja bio je eksperimentalan s dvjema paralelnim skupinama. Na početku je odlučeno da će sudjelovati 90 ispitanika $i$ to studenti dentalne medicine od prve do pete godine sa Sveučilišta u Rijeci, u dobnom rasponu od 19 do 27 godina. Kriteriji za sudjelovanje bili su prirodni zubi od prvoga kutnjaka do prvoga kutnjaka u objema čeljustima. Kriteriji za isključivanje bili su ortodontsko liječenje, prednje restauracije i sindromi. Istraživanje je provedeno uz razumijevanje i potpisani pristanak svakog sudionika te potpuno u skladu s etičkim načelima. Istraživanje je odobrilo Etičko povjerenstvo fakulteta (2170-24-01-15-05). Ispitanici su nasumično podijeljeni s pomoću funkcije random between u programu Microsoft Excel u dvije skupine od po 45 ispitanika. Procjena veličine uzorka temeljila se na prethodnom istraživanju (12). Prosječna razlika parova u dimenzijama Upitnika psihosocijalnog utjecaja dentalne estetike (PIDAQ) u opetovanoj primjeni instrumenta bez ikakva dentalnog tretmana 
any dental treatment (test-retest reliability) ranged 0.19-0.71 (mean 0.4). Supposing that the difference between neutral and experimental group would be 0.4 (neutral group would have difference of means between two administration of 0.4 , while experimental double of that amount), hypothetical standard deviation in both groups of 0.6 and ratio of sample sizes in group 1 / group $2=1$, power $\beta=0.8$ and probability level $\alpha=0.05$, and 36 subjects in each group were the minimal sample size. By adding a dropout rate of $20 \%$, a total number of 86 was reached. Therefore, 90 subjects were initially recruited. The calculation of the minimum required sample size was made by the use of the commercial statistical software MedCalc 14.8.1 (MedCalc Software BVBA, Ostend, Belgium). Due to incomplete questionnaires or giving up from the trial, seven subjects were excluded. Ultimately, the data from 83 subjects (61\% females) aged 19-27 years (median 21, range 20-22) were analyzed - 42 in the experimental (24 females) and 41 in the control group (27 females). Each subject was unaccompanied when watching a clip with five consecutive television commercials for a period of 1:45 minutes in a classroom. On the one hand, the experimental group watched commercials at one seating with positive visual stimuli (a body image stressor) which were showing both young men and women that are well known, successful, healthy, and happy. Furthermore, they had beautiful smiles, bright teeth and no visible malocclusions, accentuated in first plan, which advertised body and face creams, exercise equipment and lipsticks. On the other hand, the control group watched commercials with neutral visual stimuli that were advertising dog food, cars, fuel manufacturers, and sanitary napkins. Within the controlled group, only one commercial presented people, however, frowning and with no visible signs of teeth. A month before the exposure to visual stimuli and immediately after the exposure the respondents filled in the questionnaires which assessed the perception of their own orofacial esthetics and its psychosocial effects. One month was considered to be sufficient time for respondents to think over all aspects and roles in social interactions prior to exposure. Validated Croatian versions of psychometric instruments were used: Oral Health Impact Profile (OHIP), Orofacial Esthetic Scale (OES) and PIDAQ (12-14). PIDAQ contains 23 statements for assessing specific aspects of dental esthetics-related quality of life, grouped into four dimensions: Dental Self-Confidence (DSC; 6 items; range $0=$ low/not at all-24=high/very much), Social Impact (SI; 8 items; range 0=low-24=high) Psychological Impact (PI; 6 items; range $0=$ low-32=high) and Aesthetic Concern (AC; 3 items; range $0=$ low-12=high) (12). $\mathrm{OES}$ is a one-dimensional instrument composed of 8 items for measuring satisfaction with defined elements of orofacial esthetics through Likert scale (range 8=completely dissatisfied $-40=$ completely satisfied) (14). OHIP is a multidimensional questionnaire that assesses oral health-related quality of life. In this study, two of four dimensions were used: Orofacial Aesthetics (OFA; 6 items; range $0=$ never at all-24=very frequently) and Psychosocial Impact (PSI; 15 items; range $0=$ never at all- $60=$ very frequently) $(13,15)$.

Personality traits were expected to be stable, hence they were estimated once, a month before the exposure with the (test-retest pouzdanost) kretala se $\mathrm{u}$ rasponu od 0,19 do 0,71 (prosjek 0,4 ). Uz pretpostavku da bi razlika između neutralne i eksperimentalne skupine prosječno iznosila 0,4 (neutralna skupina imala bi razliku između dviju primjena 0,4 , a eksperimentalna dvostruko veću), uz hipotetičku standardnu devijaciju u objema skupinama od 0,6 i omjer veličina uzorka u skupini 1 i $2=1$, snagu $\beta=0,8$ i razinu vjerojatnosti $\alpha$ $=0,05$, minimalna veličina uzorka bila bi po 36 ispitanika u svakoj skupini. Dodavanjem stope odustajanja od $20 \%$ postignut je ukupan broj od 86. Zato je na početku odabrano 90 ispitanika. Izračun minimalne potrebne veličine uzorka izrađen je u komercijalnom statističkom softveru MedCalc 14.8.1 (MedCalc Software BVBA, Ostende, Belgija).

Zbog nepotpuno ispunjenih upitnika ili odustajanja od istraživanja isključeno je sedam sudionika. U konačnici su analizirani podatci 83 ispitanika (61 \% žena) u dobi od 19 do 27 godina (medijan 21, raspon 20 - 22) i to 42 u eksperimentalnoj (24 žene) i 41 u kontrolnoj skupini (27 žena). Svaki je ispitanik bio bez pratnje dok je u predavaonici gledao snimku s pet uzastopnih televizijskih reklama u trajanju od 1,45 minuta. Eksperimentalna skupina gledala je reklame s pozitivnim vizualnim podražajima (stresor slike tijela) koji su prikazivali poznate, uspješne, zdrave i sretne mladiće i djevojke. U prvom planu bili su prekrasni osmijesi i svijetli zubi bez vidljivih malokluzija, a oglašavalo se kreme za tijelo i lice, opremu za vježbanje i ruževe za usne. $S$ druge strane, kontrolna skupina gledala je reklame s neutralnim vizualnim podražajima, a teme su bile hrana za pse, automobili, proizvođači goriva i higijenski ulošci. Samo je jedna reklama u kontrolnoj skupini prikazivala ljude, no oni su bili namršteni i bez vidljivih zuba. Mjesec dana prije izlaganja vizualnim podražajima i neposredno nakon toga ispitanici su ispunili upitnike u kojima su procijenili percepciju vlastite orofacijalne estetike i njezine psihosocijalne učinke. Mjesec dana smatralo se dovoljnim razdobljem da ispitanici razmisle o svim aspektima i ulogama u društvenim interakcijama prije izlaganja. Korištene su validirane hrvatske inačice psihometrijskih instrumenata: Profil utjecaja oralnoga zdravlja (OHIP), Ljestvica orofacijalne estetike (OES) i PIDAQ (12 - 14). PIDAQ sadržava 23 izjave za procjenu specifičnih aspekata kvalitete života povezanih $s$ dentalnom estetikom, a svrstane su u četiri dimenzije: dentalno samopouzdanje (DSC; 6 izjava; raspon $0=$ nizak/uopće ne; 24 = visok/vrlo mnogo), društveni utjecaj (SI; 8 izjava; raspon $0=$ nizak; $24=$ visok), psihološki utjecaj (PI; 6 izjava; raspon $0=$ nizak; $32=$ visok) $\mathrm{i}$ estetska zabrinutost (AC; 3 izjave; raspon $0=$ nizak; 12 = visok) (12). OES je jednodimenzionalni instrument sastavljen od 8 čestica za mjerenje zadovoljstva definiranim elementima estetike zuba i lica na temelju Likertove ljestvice (raspon $8=$ potpuno nezadovoljan; 40 = potpuno zadovoljan) (14). OHIP je višedimenzionalni upitnik kojim se ocjenjuje kvaliteta života povezana $s$ oralnim zdravljem. U ovom istraživanju korištene su dvije od četiri dimenzija: orofacijalna estetika (OFA; 6 čestica; raspon 0 = nikad uopće; 24 = vrlo često) $\mathrm{i}$ psihosocijalni utjecaj (PSI; 15 čestica; raspon $0=$ nikad uopće; $60=$ vrlo često $)(13,15)$.

Očekivalo se da će osobine ličnosti biti stabilne, pa su procijenjene jedanput $\mathrm{i}$ to mjesec dana prije izlaganja s pomoću validiranih hrvatskih inačica psihometrijskih instrume- 
validated Croatian version of psychometric instruments Big Five Inventory (BFI), Rosenberg Self-esteem Scale (RSS) and Multidimensional Perfectionism Scale - Frost (MPSF) (16-18). They included extraversion $(8=$ low- $40=$ high $)$, agreeableness $(9=$ low $-45=$ high $)$, conscientiousness $(9=$ low$45=$ high $)$, neuroticism $(8=$ low $-40=$ high $)$, openness $(10=$ low$50=$ high $)$, self-esteem $(10=$ low-50=high $)$ and perfectionism in dimensions Concern over mistakes ( $9=$ low $-45=$ high), Organization $(6=$ low $-30=$ high $)$, Parental expectations $(5=$ low25=high), Personal standards (7=low-35=high), Doubts and actions ( $4=$ low-20=high), Parental criticism ( $4=$ low-20=high) and Global perfectionism (without organization) (29=low; $145=$ high).

Smile esthetics and occlusion were clinically evaluated by two examiners (AP and SS) one month before the exposure by the Index of Orthodontic Treatment Need - Dental Health Component (IOTN DHC; 1=no/minor malocclusion - 5=definite malocclusion) and Aesthetic Component (IOTN AC; range 1=best - 10=least esthetic) and the Index of Complexity, Outcome and Need (ICON; range 7=no/ minor malocclusion-120=major malocclusion) $(19,20)$. Inter- and intra-examiner reliability were assessed in 30 subjects (for inter-examiner test-retest in one-week interval). Weighted Cohen Kappa for IOTN DHC and Intraclass Correlation Coefficient for IOTN AC and ICON were used. Intra-examiner agreement ranged from $0.838-0.947$, indicating good or very good reliability. Inter-examiner agreement was somewhat lower, but still good, ranging from 0.673 to 0.758 . Inter- and intra-examiner reliability were higher for ICON, and somewhat lower for IOTN DHC and AC. Two sliding calipers the accuracy of which was 0.05 and $0.55 \mathrm{~mm}$ and precision 0.69 and $0.89 \mathrm{~mm}$ were used. The subjects reported their self-perception of smile attractiveness through IOTN AC. They reported satisfaction with teeth and facial appearance and a self-perceived need for treatment on teeth, smile and face with statements on a five level Likert scale $(0=$ not at all $4=$ very much). They reported body image, i.e. importance of teeth appearance for appearance of the body with statements on a five level Likert scale as well. The statistical analysis used the t-test for dependent and independent samples, Pearson correlation and linear regression analysis in commercial software IBM SPSS 22 (IBM Corp., Armonk, NY, USA) and MedCalc 11.2. (MedCalc Software, Mariakerke, Belgium). Statistical significance was set to $\mathrm{p}<0.05$. The effect size was calculated by the formula $\mathrm{r}=\sqrt{\mathrm{t} 2} /(\mathrm{t} 2+\mathrm{df})$, and in the interpretation the Cohen's criteria were used: $\mathrm{r}=0.1-0.3=$ small effect size, $0.3-0.5=$ medium and $>0.5=$ large.

\section{Results}

Characteristics of the sample are presented in tables 1 and 2. There were no major differences in age and gender, and, also, in most of the tested clinical and psychosocial dimensions between the active and experimental group. The subjects in the control group reported slightly higher degree of self-perceived malocclusion at the start $(2.2 \pm 1.2$ vs. $1.7 \pm 0.8$; $\mathrm{p}=0.026)$ and lower DSC (14.8 \pm 4.9 vs. $16.9 \pm 4.2 ; \mathrm{p}=0.039)$, however, with small effect sizes $(r=0.248$ and 0.237$)$. nata - Inventara velikih pet (BFI), Rosenbergove ljestvice samopoštovanja (RSS) i Frostove multidimenzionalne ljestvice perfekcionizma (MPS- F) (16 - 18). Uključivali su ekstraverziju $(8=$ niska; $40=$ visoka $)$, ugodnost $(9=$ niska; $45=$ visoka), savjesnost $(9=$ niska; $45=$ visoka $)$, neurotičnost $(8=$ niska; $40=$ visoka $)$, intelekt $(10=$ nizak; $50=$ visok $)$, samopoštovanje $(10=$ nisko; $50=$ visoko $)$ te perfekcionizam u dimenzijama zabrinutosti zbog pogrešaka $(9=$ niska; $45=$ visoka), organiziranosti ( $6=$ niska; $30=$ visoka $)$, roditeljskog očekivanja $(5=$ nisko; $25=$ visoko $)$, osobnog standarda $(7=$ nizak; 35 = visok), sumnje u vlastitu izvedbu ( $4=$ niska; 20 = visoka $)$, roditeljskog prigovaranja $(4=$ nisko; $20=$ visoko $)$ i globalnog perfekcionizama (bez organizacija) $(29=$ nizak; $145=$ visok).

Estetiku osmijeha i okluziju klinički su ocijenila dva ispitivača (A. P. i S. S.) mjesec dana prije izlaganja i to Indeksom potrebe za ortodontskim liječenjem - komponentom dentalnoga zdravlja (IOTN DHC; 1 = bez malokluzije $/ \mathrm{ma}-$ nja malokluzija; 5 = izražena malokluzija) i estetskom komponentom (IOTN AC; raspon 1 = najbolja; 10 = najmanja estetika osmijeha) te Indeksom složenosti, ishoda i potreba (ICON; raspon 7 = bez malokluzije / manja malokluzija; 120 = izražena malokluzija) $(19,20)$. Ispitivačeva pouzdanost $\mathrm{i}$ pouzdanost između ispitivača procijenjena je na 30 ispitanika (za ispitivačevu pouzdanost u intervalu od jednog tjedna). Korišteni su ponderirani Cohenov koeficijent kapa za IOTN DHC te intraklasni korelacijski koeficijent za IOTN AC i ICON. Ispitivačeva podudarnost kretala se u rasponu od 0,838 do 0,947 , što upućuje na dobru ili vrlo dobru pouzdanost. Podudarnost između ispitivača bila je nešto niža, ali i dalje dobra - u rasponu od 0,673 do 0,758. Ispitivačeva pouzdanost i pouzdanost između ispitivača bila je veća za ICON, a nešto manja za IOTN DHC i AC. Korištene su dvije pomične mjerke čija je točnost bila 0,05 i $0,55 \mathrm{~mm}$, a preciznost 0,69 i $0,89 \mathrm{~mm}$. Ispitanici su izvijestili o percepciji privlačnosti vlastita osmijeha putem IOTN AC-a. Izvijestili su o zadovoljstvu izgledom zuba i lica te o samoopaženoj potrebi za terapijom zuba, osmijeha i lica ocjenama na petostupanjskoj Likertovoj ljestvici $(0=$ uopće ne; $4=$ jako mnogo) U statističkoj analizi primijenjen je t-test za zavisne i nezavisne uzorke, Pearsonova korelacija i linearna regresija u komercijalnom softveru IBM-a SPSS 22 (IBM, Armonk, SAD) i MedCalc 11.2. (MedCalc Software, Mariakerke, Belgija) sa statističkom značajnosti od $p<0,05$. Veličina učinka izračunata je formulom $r=\sqrt{t^{2}} /\left(t^{2}+d f\right)$, a u interpretaciji su korišteni Cohenovi kriteriji: $\mathrm{r}=0,1-0,3=$ mala veličina učinka, $0,3-0,5=$ srednja $\mathrm{i}>0,5=$ velika.

\section{Rezultati}

Obilježja uzorka prikazane su u tablicama 1 i 2 . Između aktivne i eksperimentalne skupine nije bilo većih razlika u dobi i spolu, a ni u većini ispitanih kliničkih i psihosocijalnih dimenzija. Ispitanici iz kontrolne skupine izvijestili su o nešto višem stupnju samoopažene malokluzije na početku $(2,2 \pm 1,2$ vs. $1,7 \pm 0,8 ; \mathrm{p}=0,026)$ i nižem DSC-u $(14,8 \pm$ $4,9$ vs. $16,9 \pm 4,2 ; \mathrm{p}=0,039)$, ali $s$ malom veličinom učinka $(r=0,248$ i 0,237$)$. 
Table 1 Clinical estimated degree of malocclusion and subject opinions concerning orofacial esthetics

Tablica 1. Klinički procijenjen stupanj malokluzije i mišljenja ispitanika o orofacijalnoj estetici

\section{Variable (range) • varijabla (raspon)}

IOTN DHC ( 1 = no / minor malocclusion; 5 = definite malocclusion $) \bullet$ ( 1 = bez malokluzije / mala malokluzija; 5 = izrazita malokluzija $)$

Importance of teeth appearance for body image $(0=$ not at all; $4=$ very much $) \cdot$ važnost izgleda zuba za sliku tijela $(0=$ uopće ne-, $4=$ vrlo mnogo $)$

Teeth appearance satisfaction $(0=$ not at all; $4=$ very much $) \bullet$ zadovoljstvo izgledom zuba ( 0 = uopće ne; $4=$ vrlo mnogo)

Face appearance satisfaction $(0=$ not at all; $4=$ very much $) \cdot$ zadovoljstvo izgledom lica $(0=$ uopće ne; $4=$ vrlo mnogo $)$

Self -perceived need for teeth and smile treatment $(0=$ not at all, $4=$ very much $) \bullet$ samoprocijenjena potreba za terapijom zuba i osmijeha $(0=$ uopće ne, $4=$ vrlo mnogo $)$

Self-perceived need for face treatment $(0=$ not at all; $4=$ very much $) \cdot$ samoprocijenjena potreba za terapijom lica $(0=$ uopće ne; $4=$ vrlo mnogo $)$

$\mathrm{IQR}$ = interquartile range - interkvartilni raspon

\begin{tabular}{|c|c|c|}
\hline $\begin{array}{c}\text { median } \\
\text { medijan }\end{array}$ & IQR & min. - maks. \\
\hline 2 & $2-3$ & $1-4$ \\
\hline 4 & $3-4$ & $1-4$ \\
\hline 3 & $2-3$ & $0-4$ \\
\hline 3 & $2-3$ & $2-4$ \\
\hline 1 & $0-2$ & $0-4$ \\
\hline 0 & $0-1$ & $0-3$ \\
\hline
\end{tabular}

Table 2 Malocclusion severity and psychosocial profile

Tablica 2. Intenzitet malokluzije i psihosocijalni profil

Variable (range) • varijabla (raspon)

mean \pm std. deviation

prosjek \pm standardna min. - maks. devijacija

IOTN AC self-assessed ( 1 = best; 10 = least esthetic $)$ IOTN AC samoprocijenjeni ( 1 = najbolja; $10=$ najlošija estetika)

IOTN AC professionally assessed ( 1 = best; $10=$ least esthetic) $\bullet$ IOTN AC profesionalno procijenjeni $(1=$ najbolja; 10 = najlošija estetika)

ICON score ( $7=$ no/minor malocclusion; $120=$ major malocclusion $) \cdot$ ICON skor $(7=$ bez malokluzije $/$ minimalna malokluzija; 120 = izražena malokluzija)

Self-esteem $(10=$ low- $50=$ high $) \bullet$ samopoštovanje $(10=$ nisko; $50=$ visoko $)$

Extraversion $(8=$ low; $40=$ high $) \cdot$ ekstravezija $(8=$ niska; $40=$ visoka $)$

Agreeableness $(9=$ low; $45=$ high $) \cdot$ ugodnost $(9=$ niska; $45=$ visoka $)$

Conscientiousness $(9=$ low; $45=$ high $) \cdot$ savjesnost $(9=$ niska; $45=$ visoka $)$

Neuroticism $(8=$ low; $40=$ high $) \cdot$ neurotičnost $(8=$ nizak; $40=$ visok $)$

Intellect $(10=$ low; $50=$ high $) \bullet$ intelekt $(10=$ nizak; $50=$ visok $)$

Concern over mistakes $(9=$ low; $45=$ high $) \cdot$ zabrinutost zbog pogrešaka $(9=$ niska; $45=$ visoka $)$

Organization $(6=$ low; $30=$ high $) \cdot$ organiziranost $(6=$ niska; $30=$ visoka $)$

Parental expectations $(5=$ low; $25=$ high $) \cdot$ roditeljsko očekivanje $(5=$ nisko; $25=$ visoko $)$

Personal standards $(7=$ low; $35=$ high $) \bullet$ osobni standard $(7=$ nizak; $35=$ visok $)$

Doubts and actions ( $4=$ low; $20=$ high $) \bullet$ sumnja u vlastitu izvedbu ( $4=$ niska; 20 = visoka $)$

Parental criticism ( 4 = low; $20=$ high $) \cdot$ roditeljsko prigovaranje $(4=$ nisko; 20 = visoko $)$

Global perfectionism (without organisation) (29 = low;145 = high) $\bullet$ globalni perfekcionizam (bez organizacije) (29 = nizak; $145=$ visok $)$

Satisfaction with orofacial esthetics - OES $(8=$ completely dissatisfied; $40=$ completely satisfied $) \bullet$ zadovoljstvo orofacijalnom estetikom - OES ( 8 = potpuno nezadovoljstvo; 40 = potpuno zadovoljstvo)

Orofacial aesthetics - OHIP OFA $(0=$ never at all; 24 = very frequently $) \bullet$ orofacijalna estetika - OHIP OFA $(0=$ nikada; $24=$ vrlo često $)$

Psychosocial impact - OHIP PSI $(0=$ never at all; $60=$ very frequently $) \cdot$ psihosocijalni utjecaj - OHIP

PSI $(0=$ nikada, $60=$ vrlo često $)$

Aesthetic concern $-\mathrm{AC}(0=$ low; $12=$ high $) \cdot$ zabrinutost estetikom $-\mathrm{AC}(0=$ niska; $12=$ visoka $)$

Psychological impact - PI $(0=$ low; $32=$ high $) \bullet$ psihološki utjecaj - PI $(0=$ nizak; $32=$ visok $)$

Social impact - SI $(0=$ low; $24=$ high $) \bullet$ društveni utjecaj - SI $(0=$ nizak; $24=$ visok $)$

Dental self-confidence - DSC $(0=$ low; $24=$ high $) \cdot$ dentalno samopouzdanje - DSC $(0=$ nisko; $24=$ visoko)

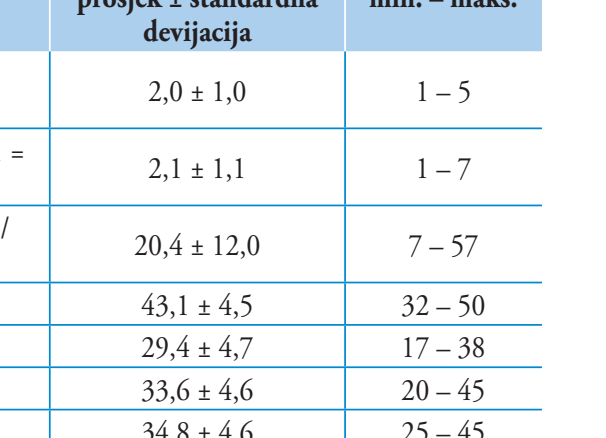

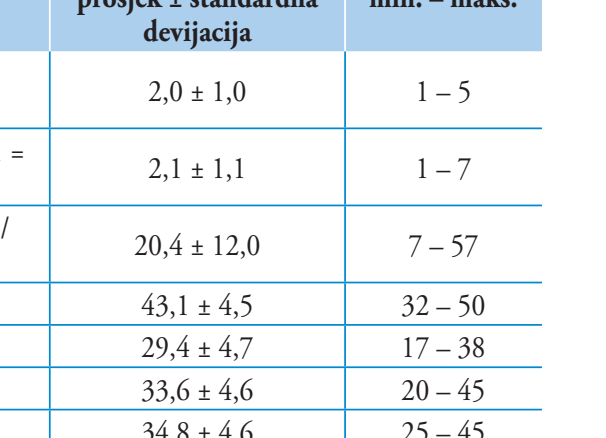

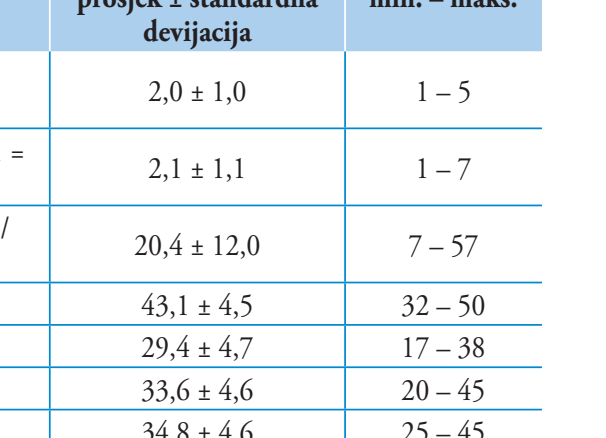

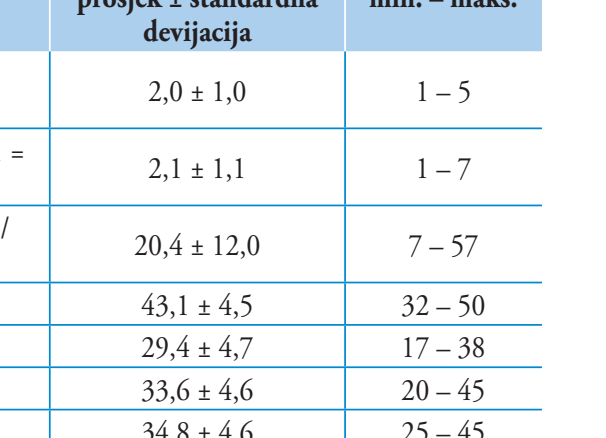

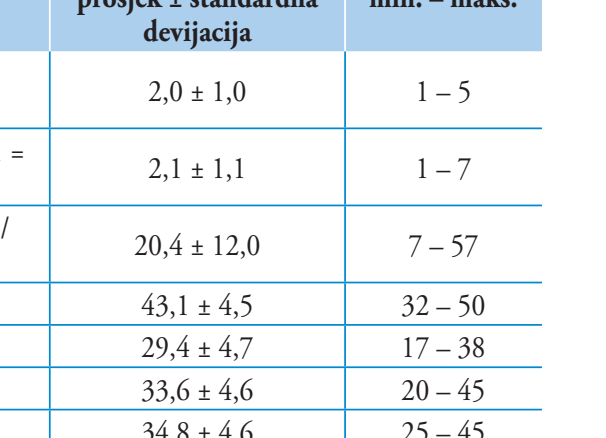


thetics, more with PIDAQ dimensions than OHIP (Table 3). Satisfaction with orofacial esthetics and psychosocial impacts of dental esthetics did not depend on the body image, and they were poorly related to personality traits (Table 3 ). Selfesteem correlated with all used instruments of quality of life, the most being DSC and AC (Table 3). Perfectionism was an important determinant of psychosocial impact of dental esthetics and orofacial appearance, mostly due to dimension Concern over mistakes (Table 3).

In their second report, after the exposure to commercials, the respondents tended to report a smaller amount of psychosocial impacts, regardless of gender (Figure 1). The differ- tike, više s dimenzijama instrumenta PIDAQ negoli OHIPa (tablica 3). Zadovoljstvo orofacijalnom estetikom i psihosocijalni utjecaji dentalne estetike nisu ovisili o slici tijela te su bili slabo povezani s osobinama ličnosti (tablica 3). Samopoštovanje je bilo povezano sa svim korištenim instrumentima za kvalitetu života, najviše s dimenzijama DSC-a i AC-a (tablica 3). Perfekcionizam je bio važna odrednica psihosocijalnog utjecaja dentalne estetike i izgleda orofacijalnog područja, najviše zbog dimenzije zabrinutosti zbog pogrešaka (tablica 3).

U drugom iskazu, nakon gledanja reklama, ispitanici su bili skloni navođenju manjih psihosocijalnih utjecaja, bez ob-

\begin{tabular}{|c|c|c|c|c|c|c|c|c|}
\hline Variable - varijabla & & OES & OHIP OFA & OHIP PSI & $\mathrm{AC}$ & PI & SI & DSC \\
\hline \multirow{2}{*}{ ICON score $\bullet$ rezultat } & $\mathrm{r}$ & $-0,187$ & 0,254 & 0,168 & 0,236 & 0,158 & 0,081 & $-0,362$ \\
\hline & $\mathrm{p}$ & 0,090 & 0,020 & 0,128 & 0,032 & 0,155 & 0,468 & 0,001 \\
\hline \multirow{2}{*}{ IOTN AC examinee $\bullet$ ispitanik } & $\mathrm{r}$ & $-0,215$ & 0,116 & 0,157 & 0,293 & 0,364 & 0,160 & $-0,473$ \\
\hline & $\mathrm{p}$ & 0,051 & 0,296 & 0,157 & 0,007 & 0,001 & 0,147 & $<0,001$ \\
\hline \multirow{2}{*}{ Body image $\bullet$ slika tijela } & $\mathrm{r}$ & 0,009 & 0,027 & $-0,030$ & $-0,099$ & $-0,091$ & $-0,120$ & 0,104 \\
\hline & $\mathrm{p}$ & 0,939 & 0,810 & 0,787 & 0,374 & 0,414 & 0,282 & 0,349 \\
\hline \multirow{2}{*}{$\begin{array}{l}\text { Satisfaction with teeth appearance } \bullet \text { zadovoljstvo } \\
\text { izgledom zuba }\end{array}$} & $\mathrm{r}$ & 0,569 & $-0,198$ & $-0,256$ & $-0,397$ & $-0,659$ & $-0,234$ & 0,710 \\
\hline & $\mathrm{p}$ & $<0,001$ & 0,073 & 0,020 & $<0,001$ & $<0,001$ & 0,008 & $<0,001$ \\
\hline \multirow{2}{*}{$\begin{array}{l}\text { Satisfaction with face appearance } \bullet \text { zadovoljstvo } \\
\text { izgledom lica }\end{array}$} & $\mathrm{r}$ & 0,475 & $-0,051$ & $-0,157$ & $-0,318$ & $-0,450$ & $-0,299$ & 0,502 \\
\hline & $\mathrm{p}$ & $<0,001$ & 0,652 & 0,160 & 0,004 & $<0,001$ & 0,006 & $<0,001$ \\
\hline \multirow{2}{*}{$\begin{array}{l}\text { Self-assessed treatment need smile } \bullet \text { samoprocijenjena } \\
\text { potreba za terapijom osmijeha }\end{array}$} & $\mathrm{r}$ & $-0,403$ & 0,288 & 0,408 & 0,487 & 0,593 & 0,216 & $-0,586$ \\
\hline & $\mathrm{p}$ & $<0,001$ & 0,009 & $<0,001$ & $<0,001$ & $<0,001$ & 0,051 & $<0,001$ \\
\hline \multirow{2}{*}{$\begin{array}{l}\text { Self-assessed treatment need face } \bullet \text { samoprocijenjena } \\
\text { potreba za terapijom lica }\end{array}$} & $\mathrm{r}$ & $-0,373$ & 0,172 & 0,215 & 0,321 & 0,344 & 0,259 & $-0,258$ \\
\hline & $\mathrm{p}$ & 0,001 & 0,123 & 0,052 & 0,003 & 0,002 & 0,019 & 0,019 \\
\hline \multirow{2}{*}{ Self-esteem • samopoštovanje } & $\mathrm{r}$ & 0,283 & $-0,310$ & $-0,241$ & $-0,420$ & $-0,344$ & $-0,394$ & 0,458 \\
\hline & $\mathrm{p}$ & 0,010 & 0,004 & 0,028 & $<0,001$ & 0,001 & $<0,001$ & $<0,001$ \\
\hline \multirow{2}{*}{ Extraversion $\bullet$ ekstraverzija } & $\mathrm{r}$ & 0,259 & $-0,114$ & $-0,100$ & $-0,078$ & $-0,223$ & $-0,154$ & 0,210 \\
\hline & $\mathrm{p}$ & 0,018 & 0,306 & 0,367 & 0,485 & 0,043 & 0,164 & 0,057 \\
\hline \multirow{2}{*}{ Agreeableness $\bullet$ ugodnost } & $\mathrm{r}$ & 0,237 & 0,039 & 0,051 & $-0,139$ & $-0,160$ & $-0,205$ & 0,120 \\
\hline & $\mathrm{p}$ & 0,031 & 0,726 & 0,644 & 0,210 & 0,147 & 0,063 & 0,278 \\
\hline \multirow{2}{*}{ Conscientiousness $\bullet$ savjesnost } & $\mathrm{r}$ & 0,305 & $-0,125$ & 0,017 & $-0,107$ & $-0,203$ & $-0,207$ & 0,109 \\
\hline & $\mathrm{p}$ & 0,005 & 0,258 & 0,882 & 0,336 & 0,065 & 0,061 & 0,325 \\
\hline \multirow{2}{*}{ Neuroticism $\bullet$ neurotičnost } & $\mathrm{r}$ & $-0,272$ & 0,216 & 0,194 & 0,221 & 0,203 & 0,253 & $-0,173$ \\
\hline & $\mathrm{p}$ & 0,013 & 0,050 & 0,078 & 0,044 & 0,065 & 0,021 & 0,119 \\
\hline \multirow{2}{*}{ Intellect • intelekt } & $\mathrm{r}$ & 0,026 & 0,020 & 0,078 & 0,077 & 0,040 & 0,061 & $-0,064$ \\
\hline & $\mathrm{p}$ & 0,815 & 0,858 & 0,485 & 0,490 & 0,717 & 0,582 & 0,563 \\
\hline \multirow{2}{*}{ Concern over mistakes $\bullet$ zabrinutost zbog pogrešaka } & $\mathrm{r}$ & $-0,219$ & 0,361 & 0,403 & 0,217 & 0,323 & 0,352 & $-0,174$ \\
\hline & $\mathrm{p}$ & 0,047 & 0,001 & $<0,001$ & 0,048 & 0,003 & 0,001 & 0,116 \\
\hline \multirow{2}{*}{ Organization $\bullet$ organiziranost } & $\mathrm{r}$ & 0,263 & 0,049 & 0,144 & $-0,050$ & $-0,204$ & $-0,138$ & 0,135 \\
\hline & $\mathrm{p}$ & 0,016 & 0,657 & 0,193 & 0,655 & 0,064 & 0,213 & 0,223 \\
\hline \multirow{2}{*}{ Parental expectations $\bullet$ roditeljsko očekivanje } & $\mathrm{r}$ & $-0,032$ & 0,107 & 0,265 & $-0,018$ & $-0,109$ & 0,001 & 0,185 \\
\hline & $\mathrm{p}$ & 0,776 & 0,334 & 0,015 & 0,871 & 0,328 & 0,993 & 0,095 \\
\hline \multirow{2}{*}{ Personal standards $\bullet$ osobni standard } & $\mathrm{r}$ &, 053 & 0,123 & 0,192 & 0,075 & $-0,071$ & $-0,058$ & 0,061 \\
\hline & $\mathrm{p}$ & 0,635 & 0,27 & 0,082 & 0,498 & 0,522 & 0,604 & 0,585 \\
\hline \multirow{2}{*}{ Doubts and actions $\bullet$ sumnje u vlastitu izvedbu } & $\mathrm{r}$ & $-0,230$ & 0,233 & 0,279 & 0,242 & 0,267 & 0,174 & $-0,191$ \\
\hline & $\mathrm{p}$ & 0,037 & 0,034 & 0,011 & 0,027 & 0,015 & 0.117 & 0.084 \\
\hline \multirow{2}{*}{ Parental criticism $\bullet$ roditeljsko prigovaranje } & $\mathrm{r}$ & $-0,110$ & 0,211 & 0,246 & $-0,040$ & $-0,044$ & 0.015 & 0.141 \\
\hline & $\mathrm{p}$ & 0,321 & 0,055 & 0,025 & 0,717 & 0,696 & 0,893 & 0,202 \\
\hline \multirow{2}{*}{ Global perfectionism • globalni perfekcionizam } & $\mathrm{r}$ & $-0,167$ & 0,330 & 0,434 & 0,169 & 0,152 & 0,191 & $-0,029$ \\
\hline & $\mathrm{p}$ & 0,133 & 0,002 & $<0,001$ & 0,126 & 0,170 & 0,084 & 0,797 \\
\hline
\end{tabular}


ences were small (ranging from $0-3$ scalar points on average) and less often significant in active than neutral group ( 2 out of 7 vs. 5 out of 7 aspects). Reduction of the psychological impact in neutral commercials was more pronounced than in smile commercials group with small effect size $(\mathrm{p}=0.045$; $\mathrm{r}=0.221$ ). The amount of changes had only few correlations with psychological characteristics, malocclusion severity, selfperceived treatment need, and the correlations were poor to moderate $(r \leq 0.433)$.

Stepwise regression analysis was used to explore whether personality traits in the active group incurred a change of psychological impact of dental esthetics $(\Delta=\mathrm{T} 1-\mathrm{T} 0)$, the only dimension that significantly differed between the active group and the placebo group. Self-perceived malocclusion severity (IOTN AC), treatment need and satisfaction with teeth and face appearance were used as a measure of pre-experimental smile esthetics. A moderation effect has been proven only for intellect i.e. openness to experience that acted as a suppressor $\left(\Delta \mathrm{R}^{2}=0.076 ; \mathrm{p}=0.005\right.$; total model $\left.\mathrm{R}^{2}=0.347 ; \mathrm{p}=0.033\right)$. In subjects with higher intellect, increasing the self-perceived malocclusion level induced a smaller decrease in psychological impact of dental esthetics compared with those of lower intellect (Figure 2). zira na spol, slika 1. Razlike su bile male (prosječno u rasponu od 0 do 3 skalarna boda) i rjeđe značajne u aktivnoj negoli u neutralnoj skupini ( 2 od 7 vs. 5 od 7 aspekata). Smanjenje psihološkog utjecaja kod gledanja neutralnih reklama bilo je izraženije negoli u reklama $s$ osmijehom $s$ malom veličinom učinka ( $\mathrm{p}=0,045 ; \mathrm{r}=0,221)$. Iznosi promjena imali su samo nekoliko korelacija sa psihološkim karakteristikama, intenzitetom malokluzije i samoopaženom potrebom za liječenjem, a korelacije su bile slabe do umjerene $(r \leq 0,433)$.

Stupnjevana regresijska analiza korištena je za istraživanje mijenjaju li osobine ličnosti u aktivnoj skupini psihološki utjecaj dentalne estetike $(\Delta=\mathrm{T} 1-\mathrm{T} 0)$, jedinoj dimenziji koja se značajno razlikovala između aktivne i placebo skupine. Samoopaženi intenzitet malokluzije (IOTN AC), potreba za liječenjem i zadovoljstvo izgledom zuba i lica korišteni su kao mjera estetike osmijeha prije eksperimenta. Moderacijski učinak dokazan je samo za intelekt, odnosno za otvorenost pre$\mathrm{ma}$ iskustvu koji se ponašao kao supresor $\left(\Delta \mathrm{R}^{2}=0,076 ; \mathrm{p}=\right.$ 0,005 ; ukupni model $\left.\mathrm{R}^{2}=0,347 ; \mathrm{p}=0,033\right)$. Kod osoba $s$ većim intelektom povećanje intenziteta samoopažene malokluzije izazvalo je manji pad psihološkog utjecaja dentalne estetike u usporedbi s onima s manjim intelektom, slika 2.
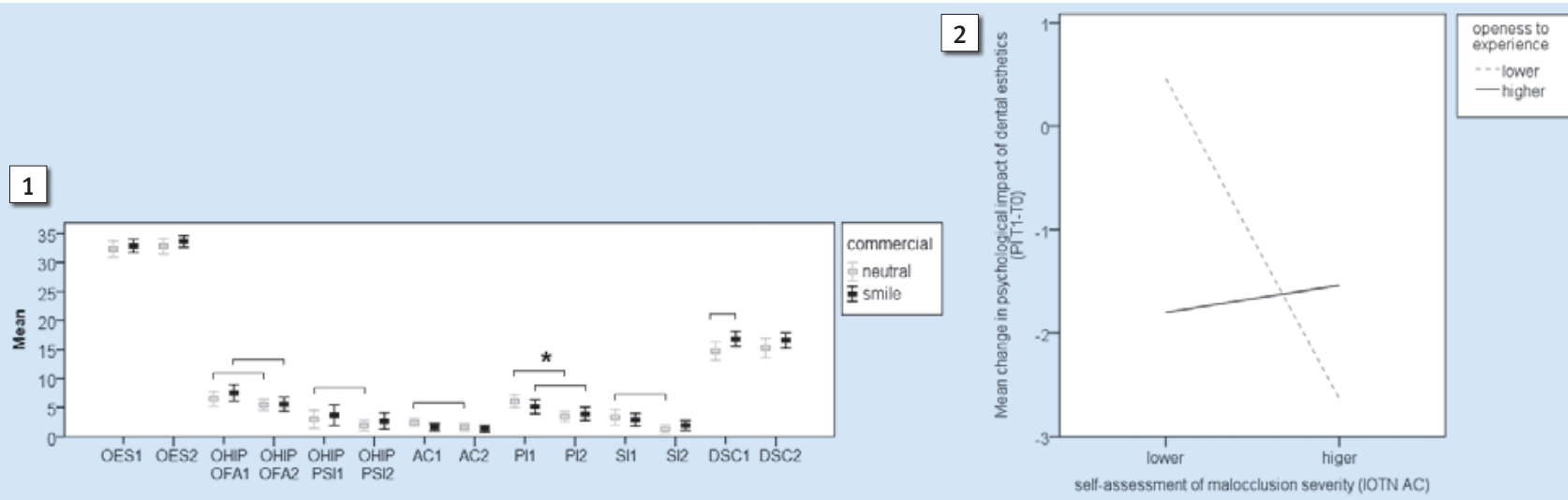

Figure 1 Comparison between perceptions of quality of life related to dentofacial esthetics between the two groups before and after the exposure to visual stimuli

Slika 1. Usporedba percepcije kvalitete života povezane s dentofacijalnom estetikom između skupina prije izlaganja vizualnim podražajima i poslije toga postupka

Figure 2 Moderation effect of intellect on the relationship between self-perceived severity of malocclusion and change of psychological impact of dental esthetics

Slika 2. Moderacijski učinak intelekta na odnos između samopercipiranog intenziteta malokluzije i promjene psihološkog utjecaja dentalne estetike

\section{Discussion}

This study confirmed the fact that satisfaction with persons' own esthetics is more related to their own perception of the condition than their actual clinical condition. Psychosocial influences of malocclusion are not stable and media can, depending on the personality, affect the perception of their own orofacial esthetics.

Contrary to what was expected, not all psychosocial impacts were related to higher clinically assessed malocclusion severity; it is mainly dental self-confidence. Psychosocial impacts were more induced by self-perceived treatment need and satisfaction with teeth appearance. Many factors apart

\section{Rasprava}

U ovoj studiji potvrđeno je da je zadovoljstvo osobnom estetikom više povezano $s$ vlastitom percepcijom stanja negoli sa stvarnim kliničkim stanjem. Psihosocijalni utjecaji malokluzije nisu stabilni i mediji mogu, ovisno o osobnosti, utjecati na percepciju osobne orofacijalne estetike.

Suprotno onomu što se očekivalo, nisu svi psihosocijalni utjecaji povezani $s$ većim klinički procijenjenim intenzitetom malokluzije - uglavnom je to dentalno samopouzdanje. Psihosocijalni utjecaji češće su potaknuti vlastitim percipiranjem potreba za liječenjem i zadovoljstvom izgledom zuba. Mnogi čimbenici, osim malokluzije (poput promjene boje, 
from malocclusion (such as discoloration, abrasion, caries, gingivitis, tooth fracture or tooth loss) cause psychosocial effects, and psychosocial effects regulate the motivation of individuals to make decisions to seek and to undergo treatment $(21-25)$. The present research also implies that women are more critical in the evaluation and they report psychosocial influences more often than men. This is in line with previous research that linked female gender with two times higher chance of dissatisfaction with their own appearance, despite the fact that dental esthetics is equally important to younger and elderly people (26).

It was expected that lower psychosocial impacts of smile esthetics are associated with higher self-esteem and extraversion, and lower neuroticism and perfectionism. According to current research, self-esteem is a characteristic which is mostly related to psychosocial influences, implying that one's overall sense of his or her value improve social interactions and empower positive emotions (17). The most significant relation is with dental self-confidence, which refers to trust in oneself and ability to deal with challenges. Therefore, the external and internal measures of value are interrelated.

Considering other personality characteristics, according to our research, the satisfaction with orofacial appearance measured by OES instrument is related to three big personality traits - extraversion, conscientiousness and neuroticism, however, it is not related to openness and agreeableness. Other authors related self-reported attractiveness of smile to extraversion and anxiety (26). Satisfaction is somewhat higher in people with higher level of extraversion who are full of energy, enthusiastic, and appreciate the participation in social gatherings (16). The subjects with low neuroticism are also more satisfied and those people have more control over their emotions, are emotionally stable and balanced. Therefore, it may be that social, talkative, active, energetic, open-minded, and dominant individuals are able to inhibit complexes, thus influencing the satisfaction with themselves (28). Satisfaction with orofacial appearance is also higher in conscious people who are organized, goal-orientated, and adhere to norms and rules (16). Individuals with these characteristics are most likely to have the will to set priorities such as obtaining and maintaining a beautiful smile by carefully performing the duties imposed by the dentist. This will lead to a beautiful and healthy smile, ultimately, to a greater satisfaction with their overall appearance (16). Psychosocial impact of dental esthetics and orofacial appearances are also related to perfectionism, but mostly due to concern over making mistakes which may also be related to conscientiousness.

The present research has implied that psychosocial influences of altered smile esthetics are not stable and mostly tend to decrease during time. This kind of dissatisfaction is mostly a more or less mild frustration due to an unfulfilled desire. Contrary to expected, positive visual stimuli of commercials showing nice teeth and smile compared to neutral ones do not induce a major change in the perception of the subject's smile esthetics, satisfaction, and psychosocial impacts. Watching commercials at one seating seems difficult to change someone's mind and his/her opinion about his/her facial esthetics. Regardless of the type of visual stim- abrazije, karijesa, gingivitisa, frakture zuba ili gubitka zuba), uzrokuju psihosocijalne učinke, a psihosocijalni učinci reguliraju motivaciju pojedinaca za donošenje odluka o traženju i podvrgavanju liječenju $(21-25)$. Sadašnje istraživanje također implicira da su žene kritičnije u procjeni i češće prijavljuju psihosocijalne utjecaje. To je u skladu s dosadašnjim istraživanjima koja su povezala ženski spol $s$ dva puta većom šansom za nezadovoljstvo vlastitim izgledom, iako je dentalna estetika podjednako važna i mlađim i starijim osobama (26).

Očekivalo se da su niži psihosocijalni utjecaji estetike osmijeha povezani s višim samopoštovanjem i ekstraverzijom te nižim neurotizmom i perfekcionizmom. Prema sadašnjem istraživanju, samopoštovanje je uglavnom povezano sa psihosocijalnim utjecajima koji impliciraju da cjelokupni osjećaj vlastite vrijednosti poboljšava socijalne interakcije i osnažuje pozitivne emocije (17). Najznačajnija povezanost je s dentalnim samopouzdanjem koje se odnosi na vjeru u sebe i sposobnost suočavanja s izazovima. Stoga su vanjska i unutarnja mjera vlastite vrijednosti uzajamno povezane.

Uzimajući u obzir ostale karakteristike ličnosti, prema našem istraživanju, zadovoljstvo orofacijalnim izgledom mjereno instrumentom OES povezano je $s$ trima velikim osobinama ličnosti - ekstraverzijom, savjesnošću i neurotizmom, ali nije povezano s intelektom i ugodnošću. Drugi su autori povezali samoprocijenjenu privlačnost osmijeha s ekstraverzijom i tjeskobom (27). Zadovoljstvo je nešto veće kod ljudi $s$ višom razinom ekstraverzije koji su puni energije, entuzijazma i cijene sudjelovanje u društvenim okupljanjima (16). Osobe s nižim neuroticizmom također su zadovoljni jer imaju veću kontrolu nad svojim emocijama, emocionalno su stabilne i uravnotežene. Dakle, moguće je da su društveni, razgovorljivi, aktivni, energični, otvoreni i dominantni pojedinci u stanju inhibirati komplekse koji utječu na zadovoljstvo samim sobom (28). Zadovoljstvo orofacijalnim izgledom veće je i kod savjesnih ljudi koji su organizirani, usmjereni na ciljeve i poštuju norme i pravila (16). Osobe $s$ tim karakteristikama najvjerojatnije imaju volju postavljati prioritete poput stjecanja i održavanja lijepog osmijeha pažljivim obavljanjem dužnosti koje postavlja stomatolog. To će dovesti do lijepog i zdravog osmijeha i, u konačnici, do većeg zadovoljstva cjelokupnim izgledom (16). Psihosocijalni utjecaj dentalne estetike i izgleda osmijeha i lica također su povezani $s$ perfekcionizmom, ali ponajviše zbog straha od pogrešaka, što može biti povezano i sa savjesnošću.

Sadašnje istraživanje nagovještava da psihosocijalni utjecaji narušene estetike osmijeha nisu stabilni i uglavnom imaju tendenciju smanjivanja tijekom vremena. Ta vrsta nezadovoljstva uglavnom je više ili manje blaga frustracija zbog neispunjene želje. Suprotno očekivanomu, pozitivni vizualni podražaji reklama u kojima se pokazuju lijepi zubi i osmijeh, u usporedbi s neutralnim, ne izazivaju veliku promjenu u percepciji vlastite estetike, zadovoljstva i psihosocijalnih utjecaja. Gledanje reklama u jednoj prilici teško da će promijeniti nečije mišljenje o vlastitoj estetici lica. Bez obzira na vrstu vizualnih podražaja, ispitanici obaju spolova drugi su put prijavili manje psihosocijalne učinke, ali prosječna je razlika bila mala - iznosila je nekoliko skalarnih bodova. Nakon prvog 
uli, the respondents of both genders reported less psychosocial impacts for the second time, but the average difference was small, amounting to few scalar points. While completing the initial questionnaire, the respondents may have realized that they were too critical towards themselves regarding their dentofacial esthetics. Therefore, a clinician should be aware that the patients' opinion and emotions related to his/ her own appearance are prone to changes even without any dental interventions. An improvement in acceptance of his/ her conditions is generally to be expected. Interestingly, the active group had a less significant reduction than the neutral group, implying that the type of visual stimuli still has an influence, but as an inhibitor of change. There was more reduction of the psychological impact of their dental esthetics with neutral commercials when compared to commercials showing beautiful teeth and smiles. Therefore, commercials portraying individuals who were smiling made some viewers consider their own smile. Some studies confirmed that media ideals cause dissatisfaction, shame, have a negative impact on self-esteem, and may create demand for dental treatments $(29,30)$. However, there are some studies which refute the abovementioned (31).

The hypothesis that a change in satisfaction related to psychosocial impacts after the exposure to commercials will be bigger in females with higher self-perceived malocclusion severity, perfectionism and neuroticism, and lower self-esteem was not confirmed. The current research shows that a particular group of people, those that are more influenced by commercials, are subjects with higher intellect who are having higher malocclusion severity. A personality trait intellect includes openness to new experiences, esthetic interests, artistic creativity, intellectual curiosity and ability to process novel stimuli quickly. Moderation effect of intellect implies that people that are more esthetically sensitive, intellectually efficient and with higher malocclusion tend to re-evaluate attractiveness of their smile when exposed to high smile esthetics of other people. The general improvement in dentofacial body image in those people is impeded during time. On the other hand, there are people closed to stimulation. They have low perceptiveness and ability to process new information and are not bothered much regardless of their malocclusion severity.

Research demonstrated that media, particularly television commercials, could have an impact on a wider audience. They start demanding different dental procedures (32). The results of psychological testing have shown that one time exposure to stimuli even for a short span, such as in commercials, can cause a change in psychosocial parameters $(33,34)$. However, the question is how long the psychological impact lasts after watching these commercials. Some studies pointed out that it is enough to show a commercial only for a few times to achieve its maximal commercial success (35). Others, however, demonstrate that repetition is very important (36). Advertising is more effective if it is repeated up to 15 times within a two-month period, and the effectiveness increases with a maximum of 12 repetitions in a two-month period. However, if the advertisement is repeated more than 15 times in a two-month period, the efficiency decreases (37). Marketers fully understand that they can have a greater effect ispunjavanja upitnika ispitanici su možda shvatili da su bili previše kritični prema sebi kad je riječ o estetici vlastita lica i zuba. Dakle, kliničar treba biti svjestan da su mišljenje i osjećaji pacijenata vezani za njegov izgled skloni mijenjaju i bez dentalnih zahvata. Općenito se može očekivati da će doći do poboljšanja u prihvaćanju vlastita stanja. Zanimljivo je da je aktivna skupina imala manje značajno smanjenje od neutralne skupine, što implicira da vrsta vizualnog podražaja ipak ima utjecaj, ali kao inhibitor promjene. Bilo je više smanjenja psihološkog utjecaja vlastite dentalne estetike kod neutralnih reklama u usporedbi s reklamama u kojima se pokazuju lijepi zubi i osmijesi. Stoga su reklame s nasmijanim osobama potaknule neke gledatelje da razmotre vlastiti osmijeh. U nekim studijama autori potvrđuju da medijski ideali izazivaju nezadovoljstvo, sram, negativno utječu na samopoštovanje i mogu potaknuti traženje dentalne terapije $(29,30)$. No u nekim se istraživanjima to odbacuje (31).

Nije potvrđena hipoteza da će promjena psihosocijalnih utjecaja zadovoljstva nakon izlaganja reklamama biti veća kod žena $s$ višim intenzitetom samopercipirane malokluzije, većim perfekcionizmom i neurotizmom te nižim samopoštovanjem. Ovo istraživanje pokazuje da reklame više utječu na određenu skupinu ljudi, a to su oni s višim intelektom i većim intenzitetom malokluzije. Intelekt je svojstvo osobnosti koje uključuje otvorenost za nova iskustva, estetske interese, umjetničku kreativnost, intelektualnu znatiželju i sposobnost za brzo obrađivanje novih podražaja. Moderacijski učinak intelekta podrazumijeva da su ljudi koji su estetski osjetljiviji, intelektualno učinkovitiji i s većom malokluzijom skloni preispitivanju privlačnosti svojega osmijeha kada su izloženi visokoj estetici osmijeha drugih ljudi. Opće poboljšanje dentofacijalne slike tijela tijekom vremena kod tih je ljudi zakočeno. Istodobno, neki su ljudi zatvoreni za stimulaciju, sa slabom percepcijom i sposobnošću da obrađuju nove informacije i njima njihovo stanje ne smeta previše, bez obzira na izraženost malokluzije.

Istraživanje je pokazalo da mediji, posebno televizijske reklame, mogu utjecati na širu publiku tako da pojedinci zahtijevaju različite dentalne zahvate (32). U psihološkom testiranju jednokratna izloženost podražajima, čak i kratka poput reklama, dovoljna je za promjenu psihosocijalnih parametara $(33,34)$. No pitanje je koliko dugo traje psihološki učinak nakon gledanja reklama. Neki kažu da je za postizanje maksimalnog komercijalnog uspjeha dovoljno prikazati reklamu samo nekoliko puta (35). Drugi, pak, ističu da je ponavljanje vrlo važno (36). Oglašavanje je učinkovitije ako se ponavlja do 15 puta u roku od dva mjeseca, učinkovitost se povećava s najviše 12 ponavljanja u razdoblju od dva mjeseca, no smanjuje se ako se oglas ponavlja više od 15 puta u dva mjeseca (37). Marketinški stručnjaci potpuno razumiju da mogu snažnije utjecati na ženske emocije, tako da su reklame namijenjene više ženama negoli adolescentima i starijoj populaciji $(38,39)$.

Ono što zabrinjava u ovoj studiji jest da su se sudionici možda željeli predstaviti u boljem svjetlu pri popunjavanju upitnika. No istraživanje je provedeno na studentima dentalne medicine koji, uzimajući u obzir njihovo obrazovanje, pokazuju višu razinu svijesti o dentofacijalnoj estetici. Stoga se 
on women's emotions, hence advertisements are designed to target women more than adolescents and elderly population $(38,39)$.

An area of concern with the study was that the participants maybe wanted to portray themselves in a better light when completing the questionnaires. However, the participants of the study were the students of dental medicine who, taking their education into account, possess a higher level of awareness about dentofacial esthetics. Therefore, it is expected that by focusing on the details, the impact of commercials could be more pronounced and evident. Thus, a suggestion for further research would be to use a broader sample of participants in order to come closer to general population.

\section{Conclusion}

Psychosocial influences of malocclusion are not stable and tend to decrease during time even without any dental interventions. However, visual stimuli in form of the exposure to a high smile esthetics of other individuals can inhibit the process in persons with higher malocclusion who have higher cognitive abilities (intellect) including higher esthetical sensitivity and openness to new experiences.

\section{Conflict of interest}

The authors do not have any conflict of interest.

\section{Acknowledge}

The study was supported by the University of Rijeka grants No. 13.06.2.1.53. and uniri-biomed-18-22.

\section{Authors' contribution}

I.L. - data collection, manuscript writing; D.KP. - data collection, critical comments on manuscript; M.B. - statistical analysis and interpretation; V.P. - manuscript writing and English language editing; A.P. - data collection, manuscript writing; S.S. - study design, data collection, statistical analysis and interpretation, supervision. može očekivati da će zbog fokusiranosti na detalje učinci reklama biti izraženiji i očitiji. Sudjelovanje studenata dentalne medicine također je nedostatak jer ta prilično specijalizirana skupina otežava generalizaciju nalaza na širu populaciju. Zato bi prijedlog za buduća istraživanja bio raznolikiji uzorak sudionika koji bi se približio općoj populaciji.

\section{Zaključak}

Psihosocijalni utjecaji malokluzija nisu stabilni i imaju tendenciju smanjivati se tijekom vremena čak i bez ikakvih dentalnih intervencija. No vizualni podražaji, u obliku izlaganja visokoj estetici osmijeha drugih ljudi, može kočiti taj proces kod osoba s višim intenzitetom malokluzije i višim intelektom koji uključuje veću estetsku osjetljivost i otvorenost prema novim iskustvima.

\section{Sukob interesa}

Autori nisu bili u sukobu interesa.

\section{Zahvala}

Istraživanje je financirano sredstvima za potporu Sveučilišta u Rijeci (13.06.2.1.53. i uniri-biomed-18-22).

\section{Doprinosi autora}

L. I. - prikupljanje podataka, pisanje rukopisa; K. P. D. prikupljanje podataka, kritički komentari o rukopisu; B. M. - statistička analiza; P. V. - pisanje rukopisa i korigiranje engleskog jezika; P. A. - prikupljanje podataka, pisanje rukopisa; S. S. - osmišljavanje studije, prikupljanje podataka, statistička analiza, supervizija.
Sažetak

Cilj: Autori studije istražili su mogu li televizijske reklame mijenjati percepciju vlastite dentofacijalne privlačnosti te je li taj proces pod utjecajem osobina ličnosti. Materijal i metode: Uzorak su činila 83 ispitanika u dobi od 19 do 27 godina. Eksperimentalna skupina $(\mathrm{N}=42)$ gledala je reklame u kojima su sudjelovali poznati mladi ljudi s visokom estetikom osmijeha, svijetlim zubima i bez vidljivih malokluzija, a kontrolnoj skupini $(\mathrm{N}=41)$ prezentirane su neutralne reklame (bez ljudi ili vidljivih zuba). Percepcija estetike vlastita lica i osmijeha te njezini psihološki učinci procijenjeni su mjesec dana prije gledanja reklama te odmah nakon toga. Procijenjeni su i intenzitet malokluzije ispitanika te osobine ličnosti (ekstraverzija, savjesnost, ugodnost, neuroticizam, intelekt, samopoštovanje i perfekcionizam). Rezultati: U svojem drugom iskazu ispitanici su imali tendenciju navoditi manje psihosocijalnih utjecaja uz male razlike (prosječno u rasponu od 0 do 3 skalarna boda) te manje značajne promjene u aktivnoj skupini negoli u neutralnoj ( 2 od 7 vs. 5 od 7 aspekata). Vrsta vizualnog podražaja bila je značajan prediktor samo promjene koja se odnosi na psihološki utjecaj dentalne estetike $(p=0,045 ; r=0,221)$. Intelekt je kao supresor oblikovao percepciju estetike osmijeha nakon gledanja reklama s naglašenim lijepim osmijesima $\left(\Delta R^{2}=0,076 ; p=0,005 ;\right.$ ukupni model $R^{2}=0,347 ; p$ $=0,033$ ). Kod osoba s većim intelektom je povećanje intenziteta samoopažene malokluzije izazvalo manji pad psihološkog utjecaja dentalne estetike u usporedbi s onima s manjim intelektom. Zaključak: Psihosocijalni utjecaji malokluzije nisu stabilni i imaju tendenciju smanjivati se tijekom vremena. No, izlaganje visokoj estetici osmijeha drugih ljudi može kočiti taj proces kod osoba s većom malokluzijom i većim intelektom.
Zaprimljen: 17. veljače 2020 . Prihvaćen: 19. srpnja 2020.

Adresa za dopisivanje prof. dr. sc. Stjepan Špalj Sveučilište u Rijeci, Fakultet dentalne medicine

Katedra za ortodonciju Kresimirova 40, 51000 Rijeka, Hrvatska

telefon: +385-51-345-638

faks: +385-51-345-630

stjepan.spalj@fdmri.uniri.hr

\section{Ključne riječi}

reklamno oglašavanje; dentalna estetika; vidno opažanje; malokluzija; osobnost 


\section{References}

1. Kuhar M. Media representation of body image and young peoples' self perception. Medij istraz. 2005;11:97-112.

2. Stephen ID, Perera AT-M. Judging the difference between attractiveness and health: does exposure to model images influence the judgments made by men and women? PLoS One. 2014 Jan 20;9(1):e86302.

3. Soderlund M, Rosengren S. The smiling face in marketing appeals and its effects on the customer. Center for consumer marketing. Stockholm School of Economics Working Paper Series in Business Administration. 2003;7:3-5.

4. Dimberg U, Thunberg M. Rapid facial reactions to emotional facial expressions. Scand J Psychol. 1998 Mar;39(1):39-45.

5. Richins ML. Social comparison and the idealized images of advertising. J Consumer Res. 1991;18:71-83.

6. King N, Touyz S, Charles M. The effect of body dissatisfaction on women's perception of female celebrities. Int J Eat Disord. 2000 Apr;27(3):341-7.

7. Sarin S, Gilbert D, Asimakopoulou K. Why simple aesthetic dental treatment in general practice does not make all patients happy. Br Dent J. 2014 Jun;216(12):681-5.

8. Murray SH, Touyz SW, Beumont PJV. Awareness and perceived influence of body ideals in the media: a comparison of eating disorder patients and the general community. Eat Disord. 1996;4:3346.

9. Ogden, J, Mundray K. The effect of the media on body satisfaction: the role of gender and size. Eur Eat Disord Rev. 1996;4:171 82.

10. Mueser KT, Grau BW, Sussman S, Rosen AJ. You're only as pretty as you feel: facial expression as a determinant of physical attractiveness. J Pers Soc Psychol. 1984;46:469-78.

11. Kiyak HA, Hohl T, Sherrick P, West RA, McNeill RW, Bucher F. Sex differences in motives for and outcomes of orthognathic surgery. J Oral Surg. 1981 Oct;39(10):757-64

12. Spalj S, Lajnert V, Ivankovic L. The psychosocial impact of dental aesthetics questionnaire - translation and cross-cultural validation in Croatia. Qual Life Res. 2014 May;23(4):1267-71.

13. Petricevic N, Celebic A, Papic M, Rener-Sitar K. The Croatian version of the Oral Health Impact Profile Questionnaire. Coll Antropol. 2009 Sep;33(3):841-7.

14. Persic S, Milardovic S, Mehulic K, Celebic A. Psychometric properties of the Croatian version of the Orofacial Esthetic Scale and suggestions for modification. Int J Prosthodont. 2011;24:523-33.

15. John MT, Feuerstahler L, Waller N, Baba K, Larsson P, Celebic A, Kende D, Rener-Sitar K, Reissmann DR. Confirmatory factor analysis of the Oral Health Impact Profile. J Oral Rehabil. 2014 Sep;41(9):644-52.

16. Schmitt DP, Allik J, McCrae RR, Bevet-Martinez V. The geographic distribution of Big Five personality traits: Patterns and profiles of human self-description across 56 nations. J Cross Cult Psychol. 2007;38:173-212.

17. Schmitt DP, Allik J. Simultaneous administration of the Rosenberg Self-Esteem Scale in 53 Nations: exploring the universal and culture-specific features of global self-esteem. J Pers Soc Psychol. 2005;89:623-42.

18. Frost RO, Marten P, Lahart C, Rosenblate R. The dimensions of perfectionism. Cogn Therapy Res. 1990;14:449-68.

19. Shaw WC, Richmond S, O'Brien KD. The use of occlusal indices: a European perspective. Am J Orthod Dentofacial Orthop. 1995 Jan;107(1):1-10.
20. Daniels C, Richmond S. The development of the index of complexity, outcome and need (ICON). J Orthod. 2000;27:149-62.

21. De Paula Junior DF, Santos NC, da Silva ET, Nunes MF, Leles CR. Psychosocial impact of dental esthetics on quality of life in adolescents. Angle Orthod. 2009 Nov;79(6):1188-93.

22. Solomon D, Katz RV, Bush AC, Farley VK, McGerr TJ, Min H, et al. Psychosocial impact of anterior dental esthetics on periodontal health, dental caries, and oral hygiene practices in young adults. Gen Dent. 2016;64:44-50.

23. Chen P, Yu S, Zhu G. The psychosocial impacts of implantation on the dental aesthetics of missing anterior teeth patients. Br Dent J. 2012 Dec;213(11):E20.

24. Gazit-Rappaport T, Haisraeli-Shalish M, Gazit E. Psychosocial re ward of orthodontic treatment in adult patients. Eur J Orthod. 2010 Aug;32(4):441-6.

25. Lin F, Ren M, Yao L, He Y, Guo J, Ye Q. Psychosocial impact of dental esthetics regulates motivation to seek orthodontic treatment. Am J Orthod Dentofacial Orthop. 2016 Sep;150(3):476-82.

26. Tin-Oo MM, Saddki N, Hassan N. Factors influencing patient satisfaction with dental appearance and treatments they desire to improve aesthetics. BMC Oral Health. 2011;11:6.

27. Van der Geld P, Oosterveldb P, Van Heckc G, Kuijpers-Jagtmand AM. Smile attractiveness: self-perception and influence on personality. Angle Orthod. 2007 Sep;77(5):759-65.

28. Gosling SD, Rentfrow PJ, Swann Jr. WB. A very brief measure of the Big-Five personality domains. J Res Pers. 2003;37:504-28.

29. Stice E, Shaw HE. Adverse effects of the media portrayed thin-ideal on women and linkages to bulimic symptomatology. J Soc Clin Psychol. 1994;13:288-08.

30. Little AC, Mannion H. Viewing attractive or unattractive same-sex individuals changes self-rated attractiveness and face preferences in women. Anim Behav. 2006;72:981-7.

31. Williams DM, Bentley R, Cobourne MT, Gibilaro A, Good S, Huppa $C$, et al. The impact of idealised facial images on satisfaction with facial appearance: comparing 'ideal' and 'average' faces. J Dent. 2008 Sep;36(9):711-7.

32. Theobald AH, Wong BKJ, Quick AN, Thomson WM. The impact of the popular media on cosmetic dentistry. N Z Dent J. 2006 Sep;102(3):58-63.

33. Walker CE, Krumhuber EG, Dayan S, Furnham A. Effects of social media use on desire for cosmetic surgery among young women. Curr Psychol. 2019

34. Newton JT, Minhas G. Exposure to ‘ideal’ facial images reduces facial satisfaction: an experimental study. Community Dent Oral Epidemiol. 2005;33:410-8.

35. Krugman HE. Why three exposures may be enough. J Advertising Res. 1972;12:11-4

36. Naples MJ. Effective Frequency: the relationship between frequency and advertising effectivenes. New York: Association of National Advertisers; 1979.

37. Pechmann C, Stewart DW. Advertising repetition: A critical rewiev of wearin and wearout. J Curr Issues Res Adv. 1992;11:283-330.

38. Lukez A, Katic V, Laus I, Grbesa M, Spalj S. Frequency, context and characteristics of smile used in advertising. Acta Stomatol Croat. 2017 Mar;51(1):41-47.

39. Carstensen LL, Mikels JA. At the intersection of emotion and cognition aging and the positivity effect. Curr Dir Psychol Sci. 2005;14:117-21. 